\title{
Optimization Mathematical Model of the Distribution of Tasks and Labor Resources in the Enterprise
}

\author{
Irina Eremina, Denis Lysanov*, Izida Ishmuradova, and Alexey Isavnin \\ Naberezhnye Chelny Institute (branch) Federal STATE Autonomous educational institution «Kazan \\ Federal University», 423812 Naberezhnye Chelny, Russia
}

\begin{abstract}
In article one of aspects of a solution of the problem of improvement of management is considered. Effective management is based on optimum use of resources and competent complex assessment of the organization. The modern IT market offers ON, capable to automate activity of any enterprise by full or partial elimination of a human factor. However in the companies where the overall performance is characterized by use of human resources, everything is not so simple. The research of authors is devoted to modeling of process of distribution of tasks and human resources by mathematical methods and combinatory optimization of process of distribution of tasks between employees within the company.
\end{abstract}

\section{Introduction}

One of the most important problems arising in various spheres of human activity is the problem of improvement of management. Effective management is based on optimum use of resources and competent complex assessment of the organization.

Information technology development caused emergence of a set of the software products designed to automate activity of any enterprise by full or partial elimination of a human factor. And if on the automated production the performance of the equipment of a vychislim, then in the companies where the overall performance is characterized by use of human resources, everything is not so simple. If to analyze a question of under what condition it is possible to reach the maximum capacity of work, then it is obvious that it is possible only at the correct distribution of internal tasks according to personnel opportunities. The complexity of their adaptation to specifics of subject domain belongs to the features which are not allowing to distribute qualitatively tasks between employees in the existing software products [1].

\section{Methods and models}

Need of automation of process of distribution of tasks is caused by a large number of structural units of the companies and lack of the suitable software. Process of the automated

\footnotetext{
* Corresponding author: DMLysanov@kpfu.ru
} 
distribution of tasks for the user consists of the following stages: data of standard reference information are entered; data for monitoring of work of employees are entered; the norm of working hours for certain calendar periods of time is established; restrictions on workload pay off; the list of tasks on an assignment is replenished; after introduction of necessary information, the user, using functionality of a system, receives the list of tasks on performance created automatically; the result of automatic distribution for receiving more effective option of use of human resources is adjusted.

Because characteristics of human resources, necessary for ensuring effective distribution, such as start date of a task, expiration date of a task, a task priority, date of introduction, the performer's holiday, have limits, when forming the list of instructions it is important to consider the restrictions imposed on them.

Treat data of restriction:

- Start date of a task has to be more or is equal to date of the earliest beginning $d t_{s}\left(w_{i}\right) \geq d t_{\min }\left(w_{i}\right)$

- Expiration date of a task has to be less or is equal to extreme date of introduction $d t_{f}\left(w_{i}\right) \leq d t_{\max }\left(w_{i}\right)$

- Start date of the following task has to be more or is equal to expiration date of a task $d t_{s}\left(w_{i+1}\right) \geq d t_{f}\left(w_{i}\right)$

- Start date of a task should not be during a holiday $d t_{s}\left(w_{i}\right) \notin$ $\left[d t_{s}\left(o\left(e_{i}\right)\right) ; d t_{f}\left(o\left(e_{i}\right)\right)\right]$

- Expiration date of a task should not be during a holiday $d t_{f}\left(w_{i}\right) \notin$ $\left[d t_{s}\left(o\left(e_{i}\right)\right) ; d t_{f}\left(o\left(e_{i}\right)\right)\right]$

- Start date of a task has to be equal to expiration date of a task of the predecessor $d t_{s}\left(w_{i}\right)=d t_{f}\left(w_{\text {pred }\left(w_{i}\right)}\right)$

- If the priority of a task is higher than a priority following, then expiration date of a task has to be less than an expiration date of the following task. If $p\left(w_{i}\right)>$ $p\left(w_{i+1}\right), d t_{f}\left(w_{i}\right)<d t_{f}\left(w_{i+1}\right)$

Treat the indicators allowing to estimate efficiency of the received decision [2]:

- average load of performers (tasks have to be distributed evenly between resources);

- the index of balance of loading of performers (has to aspire to a minimum);

- $\quad$ project terms (extreme expiration date of tasks has to aspire to a minimum).

\section{Results and discussion}

The admissible list of the distributed tasks can be considered the list in which all restrictions described in above are observed. Such distribution in which values of the specified indicators are balanced is considered effective distribution.

On the basis of the obtained and analyzed data the drawing up mathematical model of process of the distribution of tasks and human resources which is one of fundamental problems of combinatory optimization in a general view was executed.

At distribution of tasks and human resources the following sets are used [3]:

- Great number of performers $E=\left\{\operatorname{exec}_{i}\right.$, where $\left.i \in\left[1 ; N_{e}\right]\right\}$, where $N_{e}$ - number of performers.

- Set of relevant tasks $W=\left\{\right.$ work $_{j}$, where $\left.j \in\left[1 ; N_{w}\right]\right\}$, where $N_{w}$ - quantity of tasks.

- Set of complete tasks Comp $=\left\{\operatorname{comp}_{k}\right.$, where $\left.k \in\left[1 ; N_{\text {comp }}\right]\right\}$, where $N_{\text {comp }}$ number of curators.

- Great number of curators $\operatorname{Cur}=\left\{\operatorname{cur}_{m}\right.$, where $\left.m \in\left[1 ; N_{c u r}\right]\right\}$, where $N_{\text {cur }}$ - 
number of curators.

- Set of holidays $V=\left\{\right.$ vacat $_{h}$, where $\left.h \in\left[1 ; N_{v}\right]\right\}$, where $N_{v}$ - number of holidays.

- The following matrixes are used:

- Matrix of appointments $P_{e \times w}$, where $p_{i j}=1$, if the fact is approved $i$ the performer on $j$ task, otherwise $p_{i j}=0$.

- Matrix of responsible $R E S P_{e \times c u r}$, where $\operatorname{resp}_{i m}=1$, if $i$ the employee is appointed the curator $m$ performer, otherwise $r e s p_{i m}=0$.

- Matrix of criteria of efficiency of the performer $E F F_{e \times c o m p}$, where $e f f_{i k}$ - these are the valid indicators of characteristics of employees on the basis of complete tasks.

- Employee occupation matrix $V A C_{e \times v}$, where $v a c_{i h}$ - these are the valid indicators of an operating schedule of employees on the basis of active tasks.

The problem of the automated distribution of tasks and human resources consists in use of family of methods of the branches and counts based on splitting a set of admissible decisions into subsets, that is branching, and estimation of criterion function on these subsets (calculation of borders). For convenience and unambiguity of perception criteria of efficiency normalize taking into account the following rules:

- The average load has to aspire to $U_{\text {nom }}$ (tasks have to be distributed evenly between resources).

$-\quad U=\frac{\sum_{i=1}^{N_{W}} U_{i}}{N_{e}} \rightarrow U_{\text {nom }}$

- Index of balance of loading of performers . The index of balance has to aspire to a minimum.

$-\sigma=\sqrt{\frac{\sum_{i=1}^{N_{W}}\left(U_{i}-U\right)^{2}}{N_{e}-1}} \rightarrow \min$

- Extreme expiration date of tasks has to aspire to a minimum.

$-\max \left(d t_{f}\left(w_{i}\right)\right) \rightarrow \min$

The mathematical model of this task is described by the following formula:

$$
\begin{aligned}
& \text { At the following restrictions: } \\
& \sum_{i=1}^{E} \sum_{j=1}^{W} C(i, m)\left(\sum_{h}^{V} \sum_{k}^{C O M P} \sum_{m}^{C U R} p_{i j h k m}\right) \rightarrow \min \\
& \sum_{j=1}^{W} p_{i j h k m}=1 \text { for } i \in E \text { (1) } \sum_{i=1}^{E} p_{i j h k m}=1 \text { for } j \in W \\
& \sum_{\substack{h \\
\text { COMP }}}^{V} p_{i j h k m}=\text { vac }_{\text {ih }}, \text { where } i=1, \ldots, E, h=1, \ldots, V \\
& \sum_{i=1}^{E} C(i, m)\left(\sum_{k}^{\substack{h \\
\text { COMP }}} p_{i j h k m}\right)=\text { eff } f_{i k}, \text { where } i=1, \ldots, E, k=1, \ldots, \text { COMP } \\
& \sum_{i=1}^{E} C(i, m)\left(\sum_{m}^{C U R} p_{i j h k m}\right) \leq r e s p_{i m}, \text { where } i=1, \ldots, E, m=1, \ldots, C U R
\end{aligned}
$$


Variable $p_{\text {im }}$ represents appointment of the performer $i$ for work $m$, equals 1 , if the appointment fact, otherwise 0 is approved.

$p_{\text {imhbz }} \geq 0$ for $i, m \in W, E$

Restriction (1) designates that to each performer one task is appointed in accuracy. Restriction (2) designates that for each task one performer is appointed. Restriction (3) designates that by drawing up the list of tasks it is necessary to consider only employees whose holiday and terms of performance of the current task are not crossed with dates of performance of the appointed task. Restriction (4) designates that at distribution of tasks it is required to consider criteria of efficiency of employees. Restriction (5) designates that at distribution of instructions each performer needs to consider unambiguous appointment of curators.

\section{Summary}

Thus, in a research universal criteria for evaluation of efficiency of activity of staff of any enterprise regardless of the internal organization and specifics of subject domain are defined and calculated. The existing algorithms of the solution of problems of combinatory optimization in the field of mathematical optimization or a research of operations are studied.

The algorithm of distribution of tasks is based on mathematical model of a system [4]. For this model it is possible to formulate an algorithm in the form of the following sequence of steps:

1. to receive the list of tasks on distribution;

2. to receive a great number of candidate performers;

3. to create a matrix of appointments;

4. to define an optimal solution.

At realization of this algorithm means of IT the list of distribution of tasks and human resources at the enterprise is formed by the responsible user and can be corrected in real time. At the same time without fail the task is created with the indication of priorities of ordering by the performer of the tasks of the priority presented in table 1 :

Table 1. Task priority order

\begin{tabular}{|l|l|}
\hline \multicolumn{1}{|c|}{ Priority order } & \multicolumn{1}{c|}{ Description } \\
\hline High & $\begin{array}{l}\text { The task needs to be distributed first of all } \\
\text { with establishment of time of the beginning } \\
\text { of its performance right after the end of } \\
\text { distribution. }\end{array}$ \\
\hline Average & $\begin{array}{l}\text { The task should be carried out after tasks } \\
\text { with a priority "High", but whenever possible } \\
\text { the performer who does not have relevant } \\
\text { tasks at the time of distribution. }\end{array}$ \\
\hline Low & $\begin{array}{l}\text { The task is distributed in the last turn, the } \\
\text { major factor is the date of introduction which } \\
\text { is not going beyond the established time } \\
\text { frames. }\end{array}$ \\
\hline
\end{tabular}

The great number of candidate performers represents the list of all staff of the company, irrespective of their accessory to divisions, a sort of solvable tasks and employment as all human resources of the company with uniform loading depending on operating schedules are distributed.

At calculation of criteria of efficiency of employees the algorithm initially sets three levels of efficiency on all indicators presented in table 2: 
Table 2. Levels of efficiency of the employee

\begin{tabular}{|l|l|}
\hline \multicolumn{1}{|c|}{ Efficiency level } & \multicolumn{1}{c|}{ Description } \\
\hline Base (1) & $\begin{array}{l}\text { Starting point from which the result is counted. The } \\
\text { worst value. }\end{array}$ \\
\hline Efficiency level & Description \\
\hline Norm (2) & $\begin{array}{l}\text { Level which has to be without fail reached taking } \\
\text { into account all circumstances. }\end{array}$ \\
\hline Purpose (3) & $\begin{array}{l}\text { Level to which it is necessary to aspire, some kind of } \\
\text { ideal indicator. }\end{array}$ \\
\hline
\end{tabular}

Three key criteria are estimated: quantity, quality, terms of performance of work [5]. For each of indicators the weight in a percentage equivalent is established: quantity $-35 \%$, quality $-40 \%$, terms $-25 \%$. Assessment by criteria is calculated as the work of level of efficiency on indicator weight transferred to percent [6]. The additional normalizing values are areas of specialization of employees $\left(0<w_{1}<5\right)$ and their certificates confirming qualification $\left(0<w_{2}<10\right)$.

For drawing up a matrix of appointments and definition of an optimal solution the algorithm of integer programming, namely a method of "branches and borders" is used [7].

1. Names of fields appoint unique identifiers of performers, names of records unique identifiers of tasks. The matrix is initialized by cost values of tasks.

2. In every line of a matrix of appointments there is the minimum element and is subtracted from each element of a line. Thereby in a matrix not less than one element, equal to zero will appear.

3. In each column of a matrix of appointments there is the minimum element and on condition of absence in a column of zero is subtracted from column elements.

4. Couple of applicants (the performer - a task) get out to branching for which the value of a cell is equal to zero. The coefficient by addition of the minimum value of an element of a line of a task and the minimum value of a column - the performer pays off. Gets out of all coefficients maximum, the optimal solution thereby is defined and the problem of the current line is appointed to the performer of the current field.

5. As to each performer only one work is appointed, we delete the performer and a task from a matrix.

The description of an algorithm is made by means of flowcharts. Use of elements of flowcharts is regulated by GOST 19.701-90 "The uniform system of program documentation. Schemes of algorithms, programs, data and systems." 


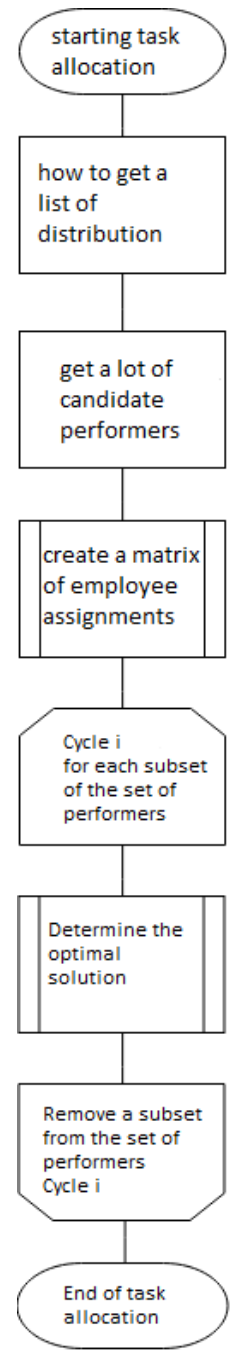

Fig. 1. Main flowchart of an algorithm of distribution of tasks 


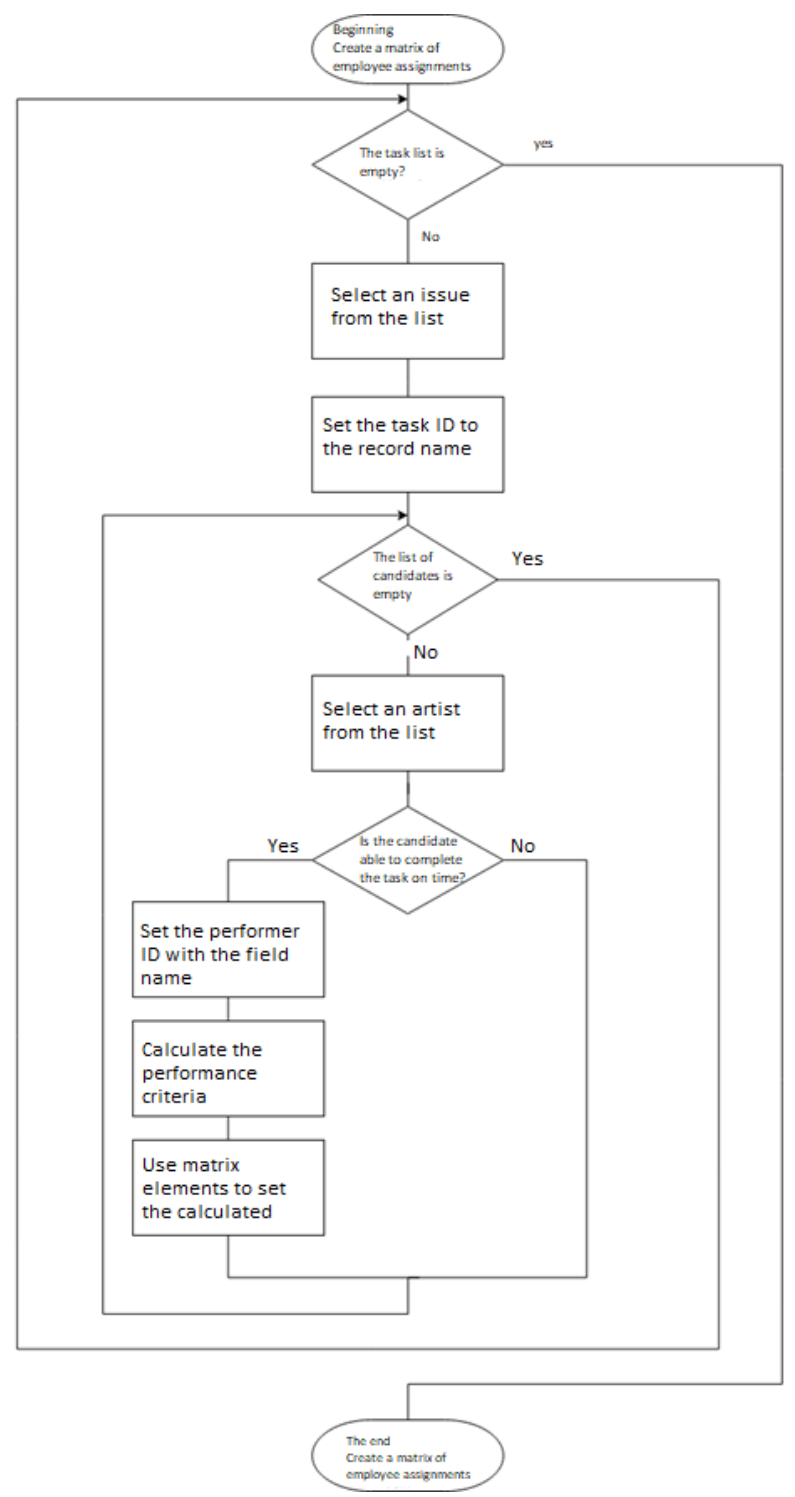

Fig. 2. The flowchart of process "To make a matrix of appointments of employees" 


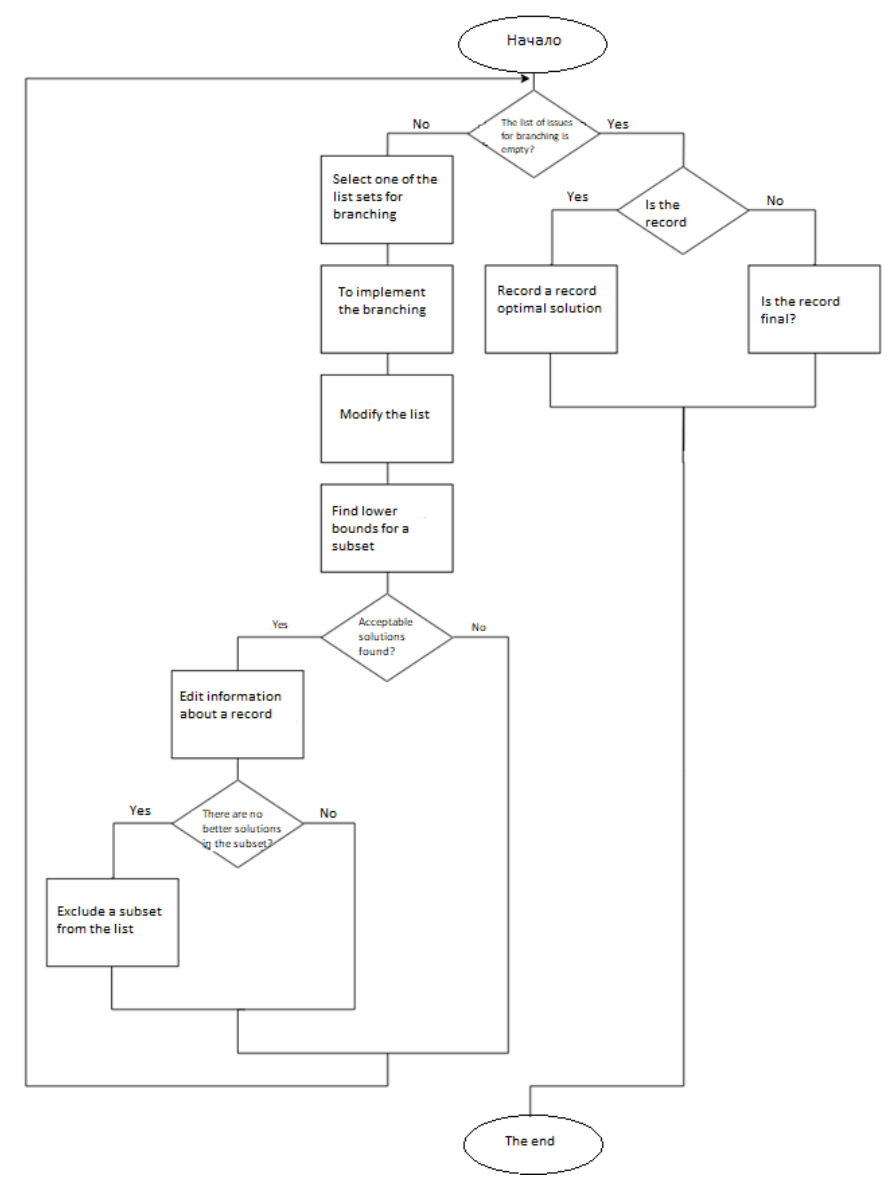

Fig. 3. The flowchart of process "To define an optimal solution"

\section{Conclusions}

On the basis of the studied approaches to management of the organizations, types of structures of management and types of production structures of the enterprise, the mathematical model of optimization of process of distribution of tasks and human resources at the enterprise and an algorithm of its realization is created by means of IT [8].

Universal criteria for evaluation of efficiency of activity of staff of any enterprise regardless of the internal organization and specifics of subject domain are defined and calculated.

The algorithm of the automated distribution of instructions on the example of test data is made. By results of testing it was succeeded to define the recommended equipment room and a program part of means of start of the used platform, adjustments and completions of the applied decision concerning logic of the program are executed.

\section{References}

1. I. Ishmuradova, A. Karamyshev, D. Lysanov, A. Isavnin, I. Eremina, Works - the International conference on developments in the field of development of electronic systems, DeSE, October-2019, 370 
2. Performing discipline as a key performance indicator, https://www.sekretariat.ru/

3. I. Ishmuradova, A. Karamyshev, D. Lysanov, A. Isavnin, I. Eremina, Works - the International conference on developments in the field of development of electronic systems, DeSE, October-2019, 773

4. Metrics of efficiency of distribution of human resources, http://miit.ru/

5. I. Ishmuradova, A. Karamyshev, D. Lysanov, A. Isavnin, I. Eremina, Works - the International conference on developments in the field of development of electronic systems, DeSE, October-2019, 284

6. I.P. Klyuev, V.A. Prikhodko, I.V. Trofimenko, The Technical and economic bulletin of Russian aluminum, 22 (2012)

7. Statement of tasks to employees of different level, https://marketing.wikireading.ru/39830

8. I. Ishmuradova, A. Karamyshev, D. Lysanov, A. Isavnin, I. Eremina, Works - the International conference on developments in the field of development of electronic systems, DeSE, October-2019, 180 